Conclusions: The Italian specialised nurses use CF quite frequently and believe that their use has the capacity of positively influencing the clinical outcome. Larger surveys are needed to understand the proportion of use of CF by nurses in common clinical practice in Italy.

References:

[1] Miller LR, Miller FG. Understanding placebo effects: Implications for nursing practice. Nurs Outlook. 2015 Sep-Oct;63(5):601-6.

[2] Häuser W, Hansen E, Enck P. Nocebo phenomena in medicine: their relevance in everyday clinical practice. Dtsch Arztebl Int. 2012 Jun;109(26):459-65.

[3] Palese A, Rossettini G, Testa M. Placebo and nocebo responses in nursing practice: a discussion paper on the role of contextual factors. In revision at Nurs Inq.

Disclosure of Interest: None declared

DOI: 10.1136/annrheumdis-2017-eular.4379

\section{AB1224-HPR COULD WE USE THE LAY REFERRAL SYSTEM TO IMPROVE THE EARLY ARTHRITIS CLINIC EFFICIENCY?}

M. Dobroiu ${ }^{1}$, M. Trandafir ${ }^{1}$, C. Ioan ${ }^{1}$, D. Vasile ${ }^{1}$, D. Predeteanu ${ }^{2}$, R. Ionescu ${ }^{2}$, F. Berghea $^{2}$ on behalf of RCRD. ${ }^{1}$ Rheumatology, Sf. Maria Hospital;

${ }^{2}$ Rheumatology, Carol Davila University of Medicine and Pharmacy, Bucharest, Romania

Background: The professional's monopoly on knowledge about disease and its treatment is something gone now, in the era of internet and patient consumerism. In addition, the interest of rheumatologists (and the interest of the society, too) shifted toward early recognition of the disease and early arthritis clinics. Education is definitely one of the solutions to increase the awareness of potential patients regarding rheumatic diseases. However most of rheumatic diseases are not very frequent in the population that raise the problem of cost efficacy of the education process. Per Eliot Freidson's view, the members of every community of whatever kind share some cultural understandings about disease, treatment, and cure. The lay community network could be considered an instrument for dissemination of proper knowledge regarding health and could help to earlier recognition of a sign of disease related to early arthritis.

Objectives: To identify the opportunity of using lay network for early arthritis referral. In addition, we intended to identify the most suitable vectors from this network to be used for education and dissemination of medical knowledge.

Methods: 48 rheumatic patients (mean age (SD): $50.8(14,7)$ ) consecutively admitted in one tertiary clinic have been invited to answer to a structured questionnaire. Sex ratio (M: F) was 1:2, average disease duration 7.7 (8.3) years. Results: In $28.3 \%$ cases the first sign of disease was noticed not by the patient but by somebody else, for $36.7 \%$ a delay of several months to one year was declared between first sign of disease and professional examination, $71.7 \%$ use to discuss bout health problems with their lay network (often and very often), $76.1 \%$ consider them able to give pertinent advices regarding the disease they suffer from, $45,7 \%$ are ready to act as an education vector and $41,3 \%$ are ready to participate in additional education programs. They interest in such activity is not related to gender, education level or work status.

Conclusions: Lay network referral could be a powerful instrument to reduce the duration between onset of rheumatic symptoms and medical visit, to increase the awareness regarding rheumatic disease, to reduce the cost of health education. Health professionals should understand how to use these networks.

\section{References:}

[1] Freidson, Eliot. 1960. "Client Control and Medical Practice." American Journal of Sociology 65:374-82.

[2] Barley, Stephen R., and Gideon Kunda. 2004. Gurus, Hired Guns, and Warm Bodies: Itinerant Experts in a Knowledge Economy. Princeton, NJ: Princeton University Press.

Disclosure of Interest: None declared

DOI: 10.1136/annrheumdis-2017-eular.4241

\section{AB1225-HPR A PROGRAM BASED ON PSYCHOEDUCATION FOR RHEUMATOID ARTHRITIS PATIENTS}

P. Osorio $^{1}$, L. Villarreal ${ }^{2}$, P. Santos-Moreno ${ }^{3}$, D. Buitrago-Garcia ${ }^{4}$, G. Cajiao ${ }^{5}$, A.M. Orozco ${ }^{5} .{ }^{1}$ Psychology; ${ }^{2}$ Psychology and processes; ${ }^{3}$ Rheumatology; ${ }^{4}$ Epidemiology, Biomab, Center for Rheumatoid Arthritis, Bogota; ${ }^{5}$ Psychology, El Bosque University, Bogota, Colombia

Background: The National Institute of Arthritis and Musculoskeletal and Skin Diseases defines rheumatoid arthritis (RA) as a chronic disease that affects the joints, causing pain, swelling, stiffness, reduced mobility and affection of internal organs. In order for patients to be able to learn to accept and integrate the disease as a part of theirs daily life, it is important that they have enough information and knowledge about their health condition. The strategy of psychoeducation is important because it involves the patient actively and seeks to have specialist who provide relevant, clear, and comprehensive information. In this way, a change is generated at level of beliefs and myths on the disease, and suggests suggestions for coping with situations for the management of the disease's impact on the patient's life.

Objectives: To determine the effect of a psychoeducation program on the quality of life and commitment to the treatment of patients diagnosed with RA from an specialized center in Bogotá.
Methods: We conducted a quasi-experimental study with two independent groups, one experimental and one for control. The Inclusion Criteria was: patients with RA over 30 years old that knew how to write and read with mobility resources. We excluded patients with emotional stress, stroke, and diagnosed cognitive deficit or with patients with consumption of psychoactive substance. We applied the Analog Visual Scale (EVA), a Quality of Life Questionnaire - Specific for patients with Rheumatoid Arthritis (QOL-RA). Data Analysis: when performing the normality test, the QoL-RA results were parametric and the analysis was performed with Student's $t$ test for independent measurements. On the other hand, the results of the EVA and CQR were non-parametric, for that reason we worked with the Mann Whitney U-test.

Results: We included 36 patients, men (4) and women (32), aged between 35 and 75 years, with diagnosis of RA, which belong to the integral model of RA specialized center. The subjects that patients preferred were: Disease management, changes in health condition, training in abilities for self-care among others. Statistical analysis showed that, when we evaluated quality of life T-student test did not showed any statistical differences between pre and post test results in both groups. The Man Wittney test showed statistical differences between groups $(u=70,500, z=241,500, p=, 004)$ regarding the compromise with the RA treatment, but it did not showed differences in regards of pain intensity between groups.

Conclusions: We recommend a strategy to facilitate the process of data collection in pre-test and post-test. For the next application of the program, it is suggested that the sample of patients must be increased, to increase the duration of each session and the number of sessions of the program. In order to achieve the patients' attendance at the program, maintain permanent communication (may be by telephone). To have printed or recorded material (Brochures, guides, CDs, etc.) is recommended with the most relevant to each session of the program.

Disclosure of Interest: None declared

DOI: 10.1136/annrheumdis-2017-eular.6189

\section{AB1226-HPR VACCINATION COMPLIANCE IN AUTOIMMUNE INFLAMMATORY RHEUMATIC DISEASES (AIRDS): ROLE OF SPECIALIST NURSE}

R.D. Thakran, S.S. Baghel, R. Rawat, C. Messi, S. Kapoor, S. Garg, A.N. Malaviya. Rheumatology, Indian Spinal Injuries Centre, New Delhi, India

Background: The patients with autoimmune inflammatory rheumatic diseases (AIRDs) have double the risk of infections as compared to the general population this may be due to highly inflammatory nature of the disease, the drug used, and the co-morbidities. In recent years, the efficacy of vaccinations has been proven in decreasing morbidities and mortality among these patients, hence, it reduces the cost of the treatment and improves the quality of life of the patients. However, low vaccination compliance is a global problem. Therefore, in this study, we tried to assess the effect of nursing counselling on vaccinations compliance.

Objectives: To assess the efficacy of counseling by the specialist rheumatology nurses in vaccination compliance among AIRDs patients.

Methods: - All the adult patients (>18yrs), suffering from AIRDs, were advised vaccinations between January to December 2016 were enrolled in this study. The basic demographic and disease-related data captured with details of vaccinations such as date of advice of vaccination and reasons for non-compliance were recorded. The patients were intensely counselled by specialist nurses about the importance and needs of vaccination, clarifying their doubts. Reinforcement of the same was carried out in the follow-up visits.

Results: A total of 506 patients ( 374 female, $73.9 .2 \%$ and 132 male, $26 \%$ ), with mean age 48 years, diagnoses; rheumatoid arthritis: $378(74.75 \%)$, Spondyloarthropathy: $80(15.81 \%)$ other autoimmune rheumatic disease $48(9.48 \%)$. Co-morbidities status: $309(61 \%)$ having multiple co-morbidities and $197(38.9 \%)$ have no co-morbidities. The vaccination compliance outcome is shown in table.

\begin{tabular}{|c|c|c|c|c|c|c|}
\hline Vaccine & Patients & Compliant & Non-compliant & Same day & $\begin{array}{c}\text { Within } \\
3 \text { months }\end{array}$ & $\begin{array}{l}\text { Within } \\
6-9 \text { months }\end{array}$ \\
\hline Pneumovac 23 & 506 & $456(90.1 \%)$ & 50 (9.9\%) & $306(67.1 \%)$ & 103 (22.5\%) & $43(9.4 \%)$ \\
\hline Prevnar 13 & 244 & 211 (86.4\%) & $33(13.6 \%)$ & $143(58.6 \%)$ & $61(25.0 \%)$ & 7 (3.3\%) \\
\hline Influvac & 506 & $443(87.5 \%)$ & $63(12.5 \%)$ & & & \\
\hline
\end{tabular}

Conclusions: The compliance rate of all vaccinations was highest on the same day when it was prescribed. This was despite the fact that the patients pay for their own vaccinations without any third party payment. However, the compliance decreases with increase in the period when it was prescribed with the passage of time. This suggests that intense counselling, availability of vaccines at premises (pharmacy) and administration of vaccination free of cost are a few of the contributory factors which can boost the compliance of the vaccination among patients with AIRDs

References:

[1] S.Shaffu, S.Mumtaz S, R.Neame: Vaccination in rheumatoid arthritis: Are your vaccinations up to date? Ann Rheum Dis 2013; 71:662.

[2] Gluck T. Vaccinate your immunocompromised patients. Rheumatology 2006:45:9-10

Disclosure of Interest: R. Thakran: None declared, S. Baghel: None declared, R. Rawat: None declared, C. Messi: None declared, S. Kapoor Consultant for: Advisory board of Novartis, Pfizer, S. Garg Consultant for: Advisory board of Intas, 